\title{
Population ageing: the timebomb that isn't?
}

\author{
Jeroen Spijker and John MacInnes argue that current measures of population ageing are misleading \\ and that the numbers of dependent older people in the UK and other countries have actually been \\ falling in recent years
}

\author{
Jeroen Spijker senior research fellow ${ }^{12}$, John Maclnnes professor ${ }^{1}$ \\ ${ }^{1}$ School of Social and Political Science, University of Edinburgh, Edinburgh EH8 9LD, UK ; ${ }^{2}$ Centre d'Estudis Demogràfics, Barcelona, Spain
}

Population ageing is a concern in all developed countries. For the first time, there are now more people over the age of 65 in the United Kingdom than there are children under 15 years. ${ }^{1}$ Over the past century, the proportion of over $65 \mathrm{~s}$ has grown from about one in 20 to around one in six. Although declining birth rates and infant mortality formed the basis for this growth from the end of the 19th century until the second world war, since the 1970s increasing life expectancy has been an additional driving force (fig $1 \Downarrow$ ). This population ageing has worried policy makers because for every worker paying tax and national insurance there are more older citizens, who make greater demands on social insurance, health, and welfare systems and have increasing morbidity and disability. ${ }^{2-4}$

The standard indicator of population ageing is the old age dependency ratio. It takes the number of people who have reached the state pension age and divides it by the number of working age (16-64 years) adults in order to estimate the proportion of older people relative to those who pay for them. Although the phased raising of the state pension age (from 65 for men and 60 for women) to 68 for both sexes, which will keep 3.5 million people in the working age, will initially cause the ratio to decline from today's $31 \%$ in England and Wales, by 2035 it will have risen to $37 \%$.

However, the old age dependency ratio is a poor measure of the burden of an ageing population. It counts neither the number of dependent older people nor the number who sustain them. It merely takes a cut-off point (the state pension age) and assigns adults to the two sides of the ratio accordingly. This might be a useful rule of thumb if the relative size of these two age groups tracked the volume of old age dependency, but it does not. We propose an alternative measure that gives a more accurate and very different picture and consider the implications of our results for health policy.

\section{Counting dependent older people}

Since the main factor behind the ageing population is increasing life expectancy, age is a poor measure of its burden. In 1900 mean life expectancy for a 65 year old woman in England and Wales was 11 years. Today she could expect to live another 21 years (10 and 18 years respectively for men). We can best capture this changing importance of age by realising that the age of a population comprises two components: the years lived of its members (their ages) and their years left (remaining life expectancies).

In a period of lengthening lifespans, not only does the average age of the population increase, so too does the remaining life expectancy associated with each age. ${ }^{5}$ This has substantial effects. The median age of the population did not climb above 25 until the start of the last century, since when it has risen to 40. Life expectancy has also increased across this period, so that although the median age of 24 in 1900 carried a life expectancy of 39 more years, those at the median age of 40 in 2009 could expect to live a further 42 years. In aggregate terms, the population of 2009, despite being much older as measured by years lived, was nevertheless younger than that of 1900 in terms of years left. This is crucial, because many behaviours and attitudes (including those related to health) are more strongly linked to remaining life expectancy than to age..$^{6-8}$

The old age dependency ratio defines all people above the statutory pension age as dependent, regardless of their economic, social, or medical circumstances. This overlooks the fact that rising life expectancy makes these older people "younger," healthier, and fitter than their peers in earlier cohorts. Many have accumulated substantial assets. Currently over one million are still working, mostly part time, many with valuable experience or specialist knowledge. The spending power of the "grey pound" has risen inexorably. Many do volunteer work vital to the third sector or look after grandchildren. We know that most acute medical care costs occur in the final months of life, with the age at which these months occur having little effect. ${ }^{9}{ }^{10}$ At least some forms of disability are being postponed to later ages. Good data on population health by age are available only for the last decade, but remaining life expectancy data are a robust substitute because they provide a more accurate picture 
of the extent of ageing. Therefore, following Sanderson and Scherbov and others ${ }^{5}{ }^{10-14}$ we use a remaining life expectancy of $\leq 15$ years as the threshold of dependency in our calculations, rather than a fixed age boundary, and do so for each sex separately.

\section{Counting the working population}

The old age dependency ratio assumes that everyone of working age actually works. However, the knowledge economy keeps young people in education for longer while many older workers choose or are obliged to retire early. Meanwhile, greater sex equality and dual career families have added five million women workers to the British labour market over the past 50 years. Using age to define the working population thus makes little sense. Indeed, if we count people who are not employed, for whatever reason, as dependent we find that there are more dependents of working age (9.5 million) than there are older people who do not work. We therefore use the number actually employed, irrespective of age, for the denominator in our calculation.

\section{Different picture of ageing}

According to the standard old age dependency ratio, for every person aged $\geq 65$ there were 7-8 adults of working age (15-64) until about 1910 (fig $2 \Downarrow$ ). The ratio subsequently increased almost linearly until about 1980, when there were just under four adults of working age for every older person. These data underpin the population ageing debate, which typically concludes that the increasing burden of elder dependency will strain health and social care systems, limit the aspirations of universal healthcare, and require raising the state pension age to limit the costs to the welfare state.

However, if we define the dependent older population as people with a remaining life expectancy of $\leq 15$ years, the trend is different. Figure $2 \Downarrow$ shows that from the late 1970 s improvements in old age mortality have reversed the rise in the proportion of the population with low life expectancies.

We can now add in the trend in employment, where later entry to employment, and earlier exit from it, has been more than offset by the large rise in employment among mothers, so that the proportion of the entire population who are at work is similar now $(48 \%)$ to what it was 60 years ago $(46 \%) .{ }^{15} \mathrm{We}$ calculated what we call the real elderly dependency ratio as the sum of men and women with a remaining life expectancy $\leq 15$ years divided by the number of people in employment. When we use this as a measure, dependency has fallen by one third over the past four decades (fig $3 \Downarrow$ ). Looking into the future, the old age dependency ratio will continue to rise, even if we adjust for the planned changes in the state pension age. However, the real elderly dependency ratio is set to fall further, stabilise for several years then gradually increase, although at no point through to 2050 will it regain the levels experienced for most of the last century. Moreover, our projection is a conservative one, since we have held employment rates constant over time, when they are likely to increase because of the rise in the state pension age, disincentives to early retirement, and further progress on sex equality. It is thus probable that our ratio will stabilise near its current level.

\section{International comparisons}

Figure $4 \Downarrow$ shows how our new measure and the conventional old age dependency ratio compare over the past half century for several countries. While the old age dependency ratio rises substantially everywhere, the real elderly dependency ratio falls in most countries. In Germany and Italy the real elderly dependency ratio has been almost flat for two decades because of slower growth in employment and lower birth rates than in other countries. Immigration has played an important role in depressing the real elderly dependency ratio by raising employment rates. Conversely Japan, with relatively low birth rates, immigration, and female labour force participation, has seen its ratio rise rapidly. Latest available data show that only the US had a lower ratio than the UK, but the UK is observing a faster rate of decline.

\section{Implications for health policy and practice}

The different story of population ageing told by our real elderly dependency ratio has several important implications for health policy and clinical practice. We should not assume that population ageing itself will strain health and social care systems. Demand for services will rise but continue to be driven by other factors, chiefly progress in medical knowledge and technology, but also the increasing complexity of comorbid age related conditions. However, as others have suggested, the economic costs of old age dependency have typically been exaggerated, especially in the UK. ${ }^{16}{ }^{17}$ Our calculations show that over the past four decades the population, far from ageing, has in fact been getting younger, with increasing numbers of people in work for every older person or child.

Medical staff will need to stay alert to the changing relation between "old" and "age" as life expectancy continues to increase and the typical onset of senescence and its associated morbidities is delayed. ${ }^{918}{ }^{19}$ Sixty may not quite be the new 40 , but expectations formed by aspiring doctors and nurses in medical school about age and morbidity or the likely health of older patients may become rapidly out of date.

More attention will need to be paid to the dynamic relation between morbidity and remaining life expectancy. Age specific disability rates seem to be falling, ${ }^{9}{ }^{20}{ }^{21}$ yet recently born generations have a worse risk factor profile than older ones. For example, current obesity trends may have a big effect on public health through related diseases such as diabetes. Ageing related diseases like osteoarthritis are predicted to increase and start at a younger age. This may not only result in an increased risk of cardiovascular and other chronic diseases, it also suggests that the ageing process can speed up as well as slow down, with obvious implications for public health policy.

We urgently need to understand the well established positive association between education and health in the context of the expansion of tertiary education since the late 1960s. It is not clear whether the improvements in adult health are an independent effect of education or a result of confounding by factors such as social class. If the effect is independent, we can expect a substantial education dividend to improve mortality and morbidity rates in the decades to come, which in turn should depress the real elderly dependency ratio.

We thank Tim Riffe, Dirk Ponsioen, Alan Swann, and the referees for their useful comments and suggestions.

Contributors and sources: JS is a demographer with research experience in population health and ageing. JM is a sociologist and social demographer with expertise in social statistics. JM prepared the initial draft, and JS did the analysis. Both authors took care of the data preparation and contributed to the final draft. JS is guarantor.

Funding: ESRC grant no ES/K004611/1 Flexible aging: new ways to measure and explore the diverse experience of population aging in Scotland, using the Scottish Longitudinal Study. 


\section{Key messages}

The extent, speed, and effect of population ageing have been exaggerated because the standard indicator-the old age dependency ratio-does not take account of falling mortality

When measured using remaining life expectancy, old age dependency turns out to have fallen substantially in the UK and elsewhere over recent decades and is likely to stabilise in the UK close to its current level

The capacity of healthcare systems to cope with increasing longevity will depend on the changing relationship between morbidity and remaining life expectancy and, in particular, the effect of education

Competing interests: We have read and understood the BMJ policy on declaration of interests and have no relevant interests to declare.

1 Office for National Statistics. National population projections, 2010-based reference volume: Series PP2. 2011. www.ons.gov.uk.

2 Doyle Y, McKee M, Rechel B, Grundy E. Meeting the challenge of population ageing. BMJ 2009;339:b3926.

3 Dyer $\mathrm{O}$. UK is urged to rethink funding of long term care of elderly people. $B M J$ 2006;332:1052.

4 Polder JJ, Bonneux L, Meerding WJ, Van Der Maas PJ. Age-specific increases in health care costs. Eur J Pub Health 2002;12:57-62.

5 Sanderson WC, Scherbov S. A new perspective on population aging. Demographic Res 2007;16:27-58.

6 Cocco JF, Gomes FJ. Longevity risk, retirement savings, and financial innovation. J Financial Econ 2012;103:507-29.

7 Hamermesh DS. Expectations, life expectancy, and economic behavior. Q J Econ 1985;100:389-408.

8 Van Solinge H, Henkens K. Living longer, working longer? The impact of subjective life expectancy on retirement intentions and behaviour. Eur J Public Health 2010;20:47-51. Christensen K, Doblhammer G, Rau R, Vaupel JW. Ageing populations: the challenges ahead. Lancet 2009;374:1196-208.

10 Sanderson WC, Scherbov S. Remeasuring aging. Science 2010;329:1287-8.
11 Lutz W, Sanderson W, Scherbov S. The coming acceleration of global population ageing. Nature 2008:451:716-9.

12 Lutz W, Sanderson W, Scherbov S. Global and regional population ageing: how certain are we of its dimensions? J Popul Ageing 2008;1:75-97.

13 Ryder NB. Notes on stationary populations. Popul Index 1975;41:3-28.

14 Lutz W. The demography of future global population aging: indicators, uncertainty, and educational composition. Popul Dev Rev 2009;35:357-65.

15 Office for National Statistics. Labour market statistics. www.ons.uk.

16 Bongaarts J. Population aging and the rising cost of public pensions. Popul Dev Rev 2004;30:1-23.

17 Mason A, Lee R, Tung A-C, Lai M-S, Miller T. Population aging and intergenerational transfers: introducing age into national accounts. NBER working paper series No 12770 2006. www.nber.org/papers/w12770.

18 Rau R, Soroko E, Jasilionis D, Vaupel JW. Continued reductions in mortality at advanced ages. Popul Dev Rev 2008:747-68.

19 Vaupel JW. Biodemography of human ageing. Nature 2010;464:536-42.

20 Crimmins EM. Trends in the health of the elderly. Annu Rev Public Health 2004;25:79-98.

21 Schoeni RF, Freedman VA, Martin LG. Why is late-life disability declining? Milbank $Q$ 2008;86:47-89.

Accepted: 21 October 2013

Cite this as: BMJ 2013:347:f6598

(c) BMJ Publishing Group Ltd 2013 


\section{Figures}

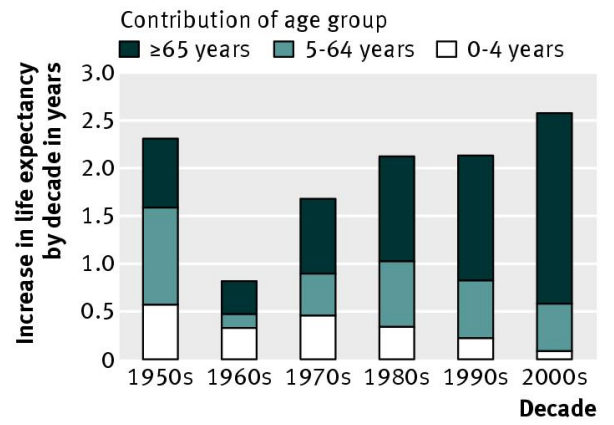

Fig 1 Change in life expectancy (in years) in England and Wales within each decade broken down by age group, 1950-2010 (data from www.mortality.org). Life expectancy increased by 2.6 years between 2000 and 2010, 0.1 years of which came from improved infant and child survival and, respectively 0.5 and 2.0 years from lower mortality among 5-64 and $\geq 65$ year olds

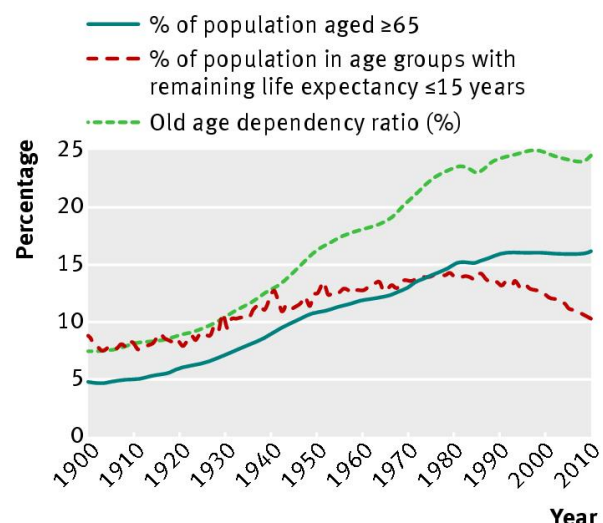

Fig 2 Proportion of the population aged $\geq 65$, proportion of the population at ages with remaining life expectancy of $\leq 15$ years, and the old age dependency ratio, England and Wales 1900-2011 (see appendix on bmj.com for calculations)

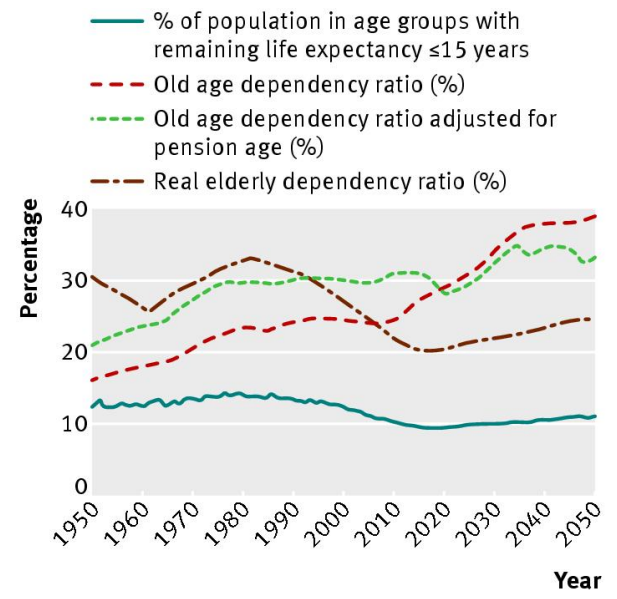

Fig 3 Old age dependency ratios, proportion of the population at ages with remaining life expectancy of $\leq 15$ years, and the real elderly dependency ratio, England and Wales 1950-2050 (data from www.mortality.org and England and Wales censuses (www.ons.gov.uk)). See appendix on bmj.com for details of calculations 


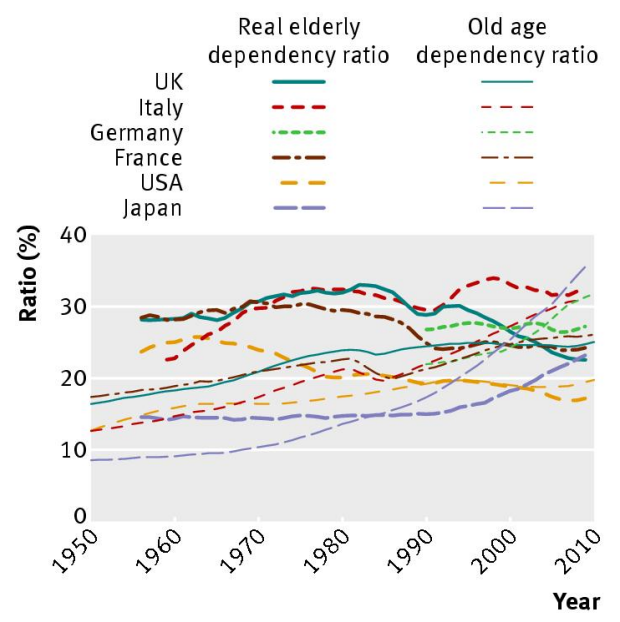

Fig 4 Real elderly dependency ratio and old age dependency ratios in various countries, 1950-2010 (data from www.mortality.org and http://stats.oecd.org) 